\title{
Lindon J. Eaves, Ph.D., M.A. (Oxon), D.Sc. Theory-Model-Data
}

\author{
Hermine H. M. Maes • Peter K. Hatemi • \\ Michael C. Neale
}

Received: 29 December 2013/Accepted: 1 April 2014/Published online: 13 May 2014

(C) Springer Science+Business Media New York 2014

\begin{abstract}
We begin this special issue by providing a glimpse into the career of Dr. Lindon J. Eaves, from the perspectives of a student, postdoc, instructor, assistant to associate and full professor over the last 20 odd years. We focus primarily on Lindon's contributions to methodological issues and research designs to address them, in particular those related to models for extended twin-family designs, for the development of adolescent behavior, for genotype-environment covariation and interaction, and their application to the Virginia 30,000 and the Virginia Twin Study of Adolescent Behavioral Development. We then introduce the collection of papers in this special festschrift issue of Behavior Genetics, celebrating Dr. Eaves achievements over the last 40 years.
\end{abstract}

Keywords Twin studies - Statistical modeling · Intergenerational transmission $\cdot$ Development

\footnotetext{
H. H. M. Maes $(\bowtie) \cdot$ M. C. Neale

Department of Human and Molecular Genetics, Virginia Institute for Psychiatric and Behavioral Genetics, Virginia Commonwealth University, PO Box 980003, Richmond, VA 23298-0003, USA

e-mail: hmaes@vcu.edu
}

\section{H. H. M. Maes}

Massey Cancer Center, Virginia Commonwealth University, Richmond, VA, USA

H. H. M. Maes · P. K. Hatemi - M. C. Neale Department of Psychiatry, Virginia Institute for Psychiatric and Behavioral Genetics, Virginia Commonwealth University, Richmond, VA, USA

H. H. M. Maes

Department of Kinesiology, Katholieke Universiteit Leuven, Leuven, Belgium

\section{Introduction}

This article serves as both an introduction to the special issue and intends to provide a glimpse into the career of Dr. Lindon J. Eaves (Photo 1), from the perspectives of students, postdocs, instructors, assistant, associate and full professors over the last 20 odd years. Given Hermine's visual learning preference, we will illustrate with photos and diagrams of various kinds. We each met Lindon in different ways, but each surrounded our desire to learn and his desire to teach. Mike first met Lindon at the International Society for Twin Studies meeting at the University of London in 1983. Lindon presented a paper on developmental models, and Mike presented a bivariate model for data from twins and their parents. Pete's first introduction to Lindon was somewhat a comedy of errors. In 2005, a group of political scientists, unfamiliar with science norms that we in Behavioral Genetics take for granted, published an article using data that Lindon had provided on the

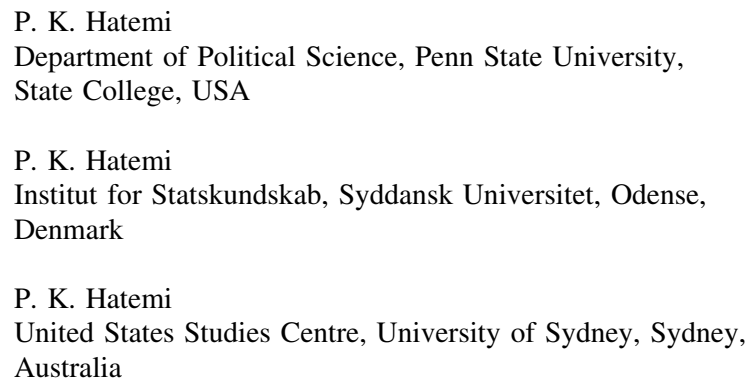




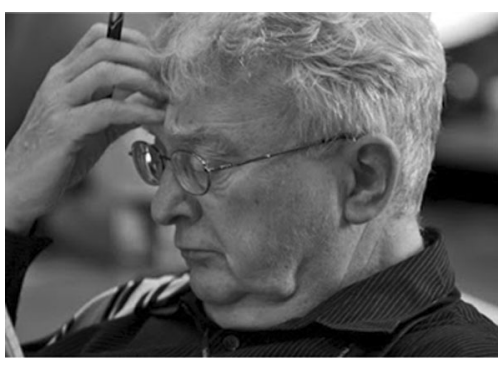

Photo 1 Taken by Michael C. Neale during anniversary workshop in Leuven, Belgium, 2008, copyright (c) the author

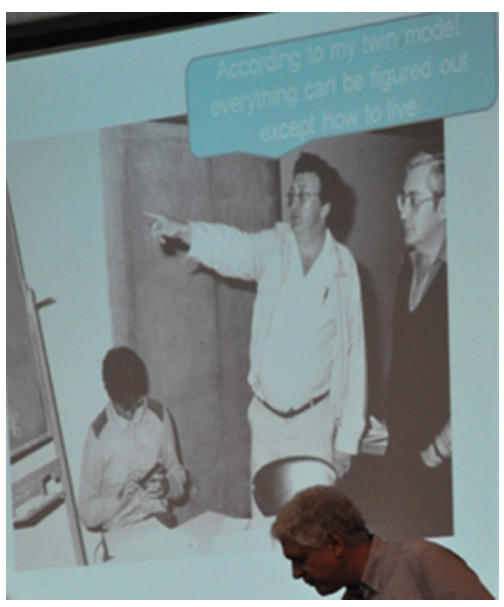

Photo 2 Taken by Hermine H. Maes during the 24th workshop in Boulder Colorado, 2010; picture in the picture taken during first workshop in Leuven, Belgium, 1987, depicting from left to right Andrew C. Heath, Lindon J. Eaves and the late David W. Fulker, copyright $(C)$ the author

expectation of being included in any article arising from analyses. Pete then independently contacted Lindon, only to receive an email back telling him to bugger off! Fortunately, Nick Martin's well known prowess in diplomacy saved the day, and the two have been close since. But, perhaps, Hermine's story serves best to set the stage for our introduction. Hermine met Lindon for the first time in September of 1986 as she witnessed him talking to a group of colleagues (including David Fulker, Andrew Heath, Nick Martin, Dorret Boomsma, Robert Derom and Robert Vlietinck, her co-advisor at the time) about the dismal state of statistical analyses applied to ever-increasing twin data sets, and proposing to organize a workshop to remedy the situation. The now well-known 'International Workshops on Twin Methodology' were the direct result from that, with the first one being taught in Leuven, Belgium in 1987 which Mike and Hermine had the good fortune to attend (Photo 2). Pete was late, as usual, arriving in 2006. These workshops became the cornerstone of training in behavior genetics and other advances in statistical genetics. They have provided a clear foundation as well as room for developments of new models and methods inspired by more complex questions, new technologies, and new types of data. In this editorial introduction, we will focus primarily on Lindon's contributions to methodological issues and research designs to address them, in particular those related to extended twin models and their application to the Virginia 30,000 study and models for the development of adolescent behavior and their application to the Virginia Twin Study of Adolescent Behavioral Development.

\section{Theory-Model-Data}

A central theme in Lindon's teachings on the causes of individual differences is depicted in the theory-model-data diagram (Fig. 1) which first appeared in his writings on the utility of twins (Eaves 1972). In various conversations, often with students, Lindon presses the importance of 'What is the question you're trying to address? Does your approach enable you to formulate your hypotheses in precise terms? Which design (i.e. constellation of relatives) will allow you to discriminate between alternative hypotheses? Does your proposed method of analysis make the best use of the available data?' (see Eaves 1979 for a more detailed account). Furthermore, when testing a chosen model to a carefully collected set of data, it is key to be cognizant of the assumptions made in the model, such that one does not overstate (or understate) the findings of the model-fitting process. It is essential to put them in light of their limitations, highlighted by a phrase often heard coming from Lindon 'Can we believe the results?'. So even though Lindon had been one of the main proponents of the classical twin design and has illustrated its power to address questions about the role of nature and nurture in individual differences, he was also keen to look beyond twins (Photo 3), to test the assumptions of the twin model, to evaluate the consistency of the results across a range of designs (i.e. replication) and to take into account all sources of variation and covariation.

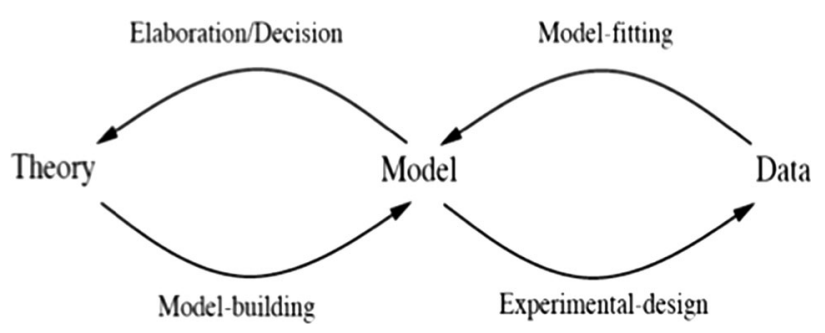

Fig. 1 First appeared in Eaves 1972, reproduced from Figure 1.6 in Neale, MC \& Cardon LR, 1992 
Photo 3 Taken by Hermine H. Maes during 2nd workshop in Leuven, Belgium, copyright (C) the author
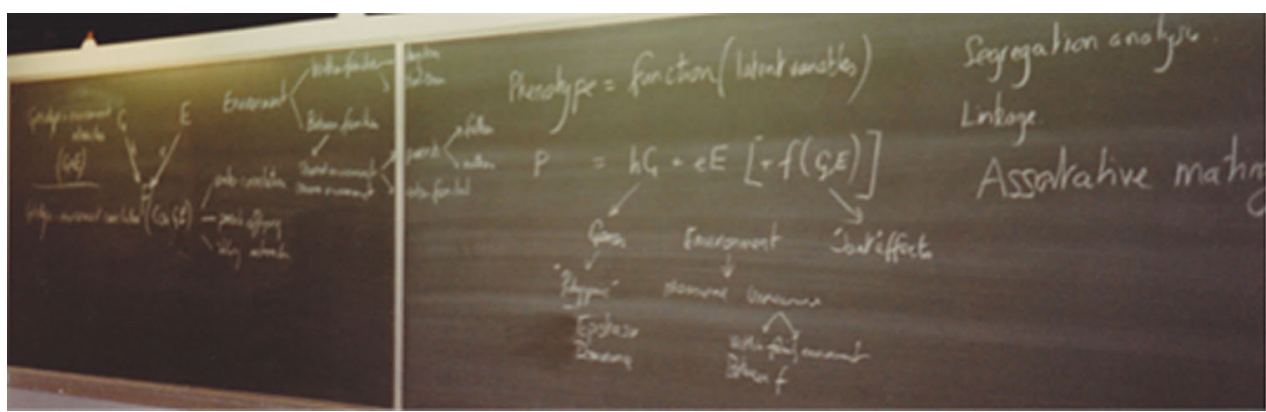

\section{Models of Intergenerational Transmission}

One of the major foci of Lindon's work is delineating the role of genes and environment through understanding pattern of transmission and interaction among relatives. In one of his early flagship papers (Eaves et al. 1978) — by the way if you think you've come up with an original data, check this 40-page paper for its originality-he uses a path model to represent the environmental effect siblings may have on one another, taking into account environmental transmission from parents to offspring' environment as well as phenotypic assortment (Fig. 2a). Thus environmental transmission can take place both across and within generations. An alternative model draws the arrows directly from the phenotype in the parents to the phenotype in the offspring ( $\mathrm{P}$ to $\mathrm{P}$ transmission, Fig. $2 \mathrm{~b}$ ), implying the parental behavior influences offspring behavior, to test cultural transmission in the presence of genetic effects (Eaves et al. 1989a, b). In what he refers to as a 'simple' path model for the biological and cultural inheritance in nuclear families' he shows that the combined effects of vertical cultural and genetic transmission will lead to

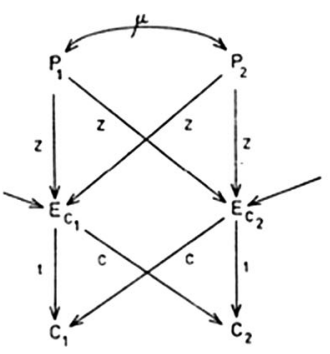

(a) Twins

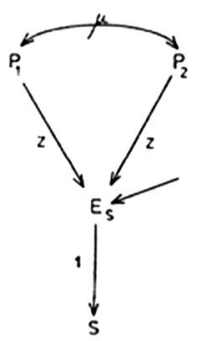

(b) Singletons

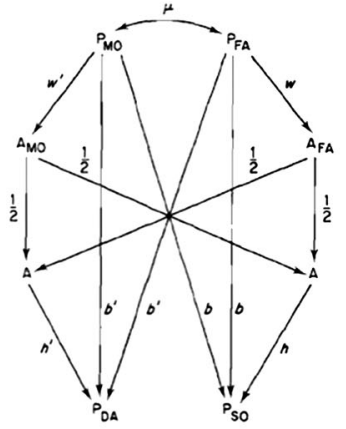

(b)

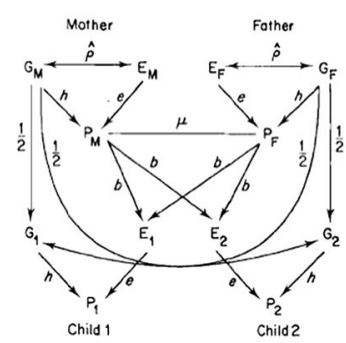

(c)

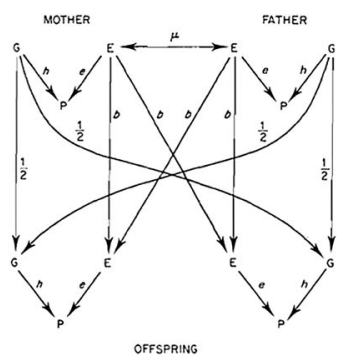

(d)

(a)

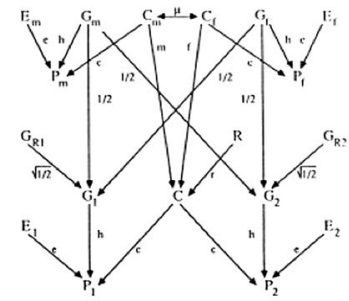

(e)

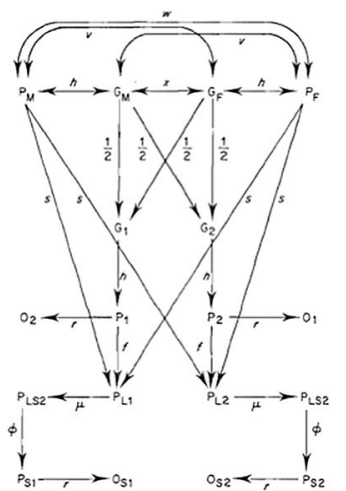

(f)

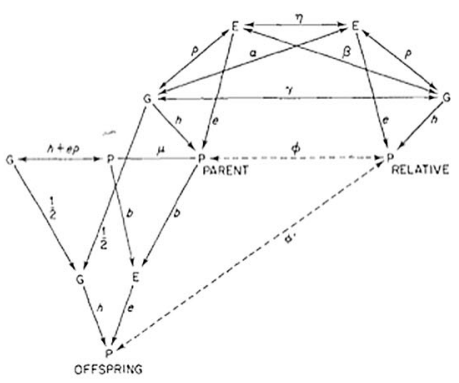

(g)
Fig. 2 a Reproduced from Fig. 1 in Eaves et al. 1978, b reproduced from Fig. 15.1 in Eaves et al. 1989a, c reproduced from Fig. 6.1 in Eaves et al. 1989a, d reproduced from Fig. 16.1 in Eaves et al. 1989a, e reproduced from Fig. 1 in Eaves et al. 1989b, f reproduced from Fig. 16.3 in Eaves et al. 1989a, g reproduced from Fig. 6.2 in Eaves et al. 1989 a 
genotype-environment covariance (Fig. 2c). Yet another possible parameterization of the parent-offspring design includes causal arrows from the parental environment to that of the offspring, in what is referred to as E to E cultural transmission, accompanied possibly by assortment for the latent environmental variable (Fig. 2d). A more extreme version of this model allows for complete assortment and perfect transmission of this latent variable. When the assortment takes place at the level of the shared environment, the process is referred to as 'social homogamy', the effects of which are passed on to the next generation through cultural transmission (Eaves et al. 1989a, b), recognizing that there may be residual (non-parental) shared environmental contributions (Fig. 2e). The simultaneous presence of phenotypic assortment and social homogamy, called mixed homogamy, leads to a complex web of intercorrelations between sources of variance (Fig. 2f). These models can be extended to include remote relatives whereby the expectations from the first degree relatives can be used to obtain those for the remote ones (Fig. 2g). Luckily, Lindon worked through the complex algebra to generate the expectations for a range of relatives under a variety of models (Fig. 3) back almost 40 years ago (Eaves 1976). In keeping with the earlier theme, each model comes with its set of assumptions, as expressed in his words 'The strength of this model lies in our ability to specify the assumptions'.

\section{Extended Twin Designs: The Virginia 30,000}

To test the various hypotheses put forth in these alternative models, an appropriate design, i.e. set of types of relatives, had to be found, and data had to be collected for a large enough sample of all these types of relative. Given Lindon had been instrumental in creating the Virginia Twin Registry, which is a population-based registry of twins born in Virginia (Lilley and Silberg 2013), and due to the power of the classical twin design, it turned out to be a good starting point for ascertainment. Twins who participated were asked to provide contact information for their first degree relatives (which would be much harder under current regulations) including their parents, siblings, spouses and children (Fig. 4a), thus generating an 'extended twin design' that comprises 88 sex-specific types of biological and social relationships. Sixteen-page questionnaires on a wide range of behaviors were mailed out to twins and their relatives and returned by close to 30,000 individuals, hence the study is referred to as the Virginia 30,000 (Eaves et al. 1999a, b). To test the alternative models to these twin pedigrees, expectations for each of the different types of relative were written and translated into Fortran code, originally run on an old mainframe computer. As the diagram representing the model looked like a stealth bomber (Fig. 4b), the model is still often referred to as the 'Stealth' Model (Eaves et al. 1999a, b). To stay in the same sphere,

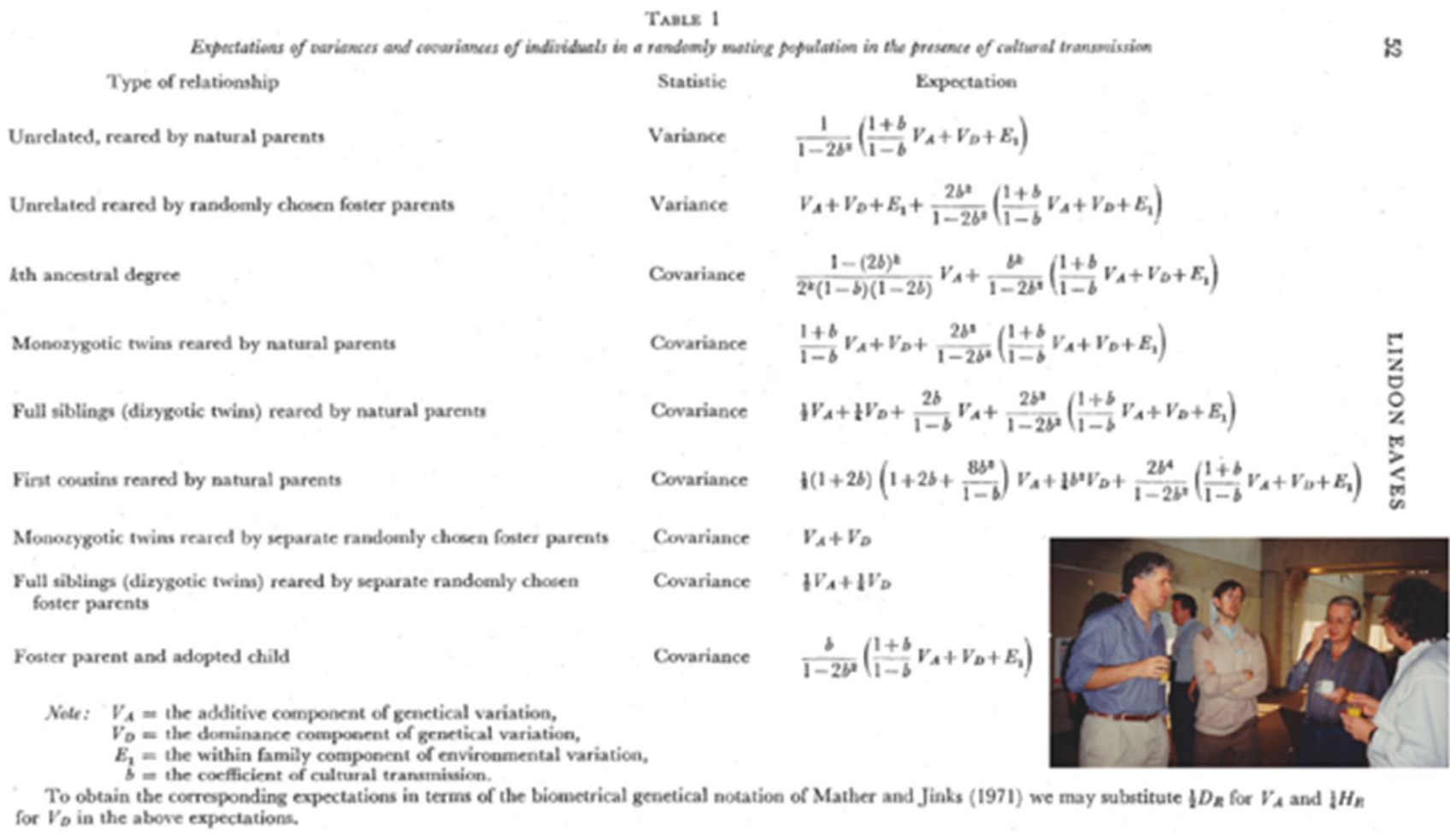

Fig. 3 Reproduced from Table 1 in Eaves 1976. Insert photo taken during the first workshop in Leuven, Belgium, 1987, copyright $(\subset)$ the author 
we call it the ET model (Fig. 4c) referring to the extended twin design (Maes et al. 1996). In an effort to make the model more accessible, we have made a few advances in the more than 20 years since its original conception. The Fortran code was first rewritten in classic Mx (Neale et al. 2006) and more recently in OpenMx (Boker et al. 2011). While the original model was fitted to observed correlations, current versions can be fit to the raw data. The univariate specification was expanded to the bivariate or multivariate case. In addition to phenotypic assortment, social homogamy can also be modeled, in the 'cascade' version (Fig. 4d) of the model (Keller et al. 2009). Extensions which allow for evaluating the effect of covariates on the means/thresholds have been incorporated, and others to test moderation of the variance components to test genotype $\mathrm{x}$ age interaction are in progress. It should come as no surprise that Lindon's intellectual pedigree will soon include 30,000 individuals, as over 1,000 people have attended workshops and lectures [not including his church sermons] who then go on to 'transmit' the information to their 'offspring'.

\section{Developmental Genetic Models}

Another theme that is dear to Lindon is that of understanding how people's behavior develops over time, and what causes their continuity or change (Photo 4). One such model not only partitions variance into genetic and environmental sources, but then breaks each source further down in contributions that are passed on from previous time points versus those that are new or specific to the current time point, or time-specific residuals (Eaves et al. 1989a, b). This model generates a specific pattern of correlations across time that is referred to as a simplex structure (Fig. 5a) with correlations between adjacent time

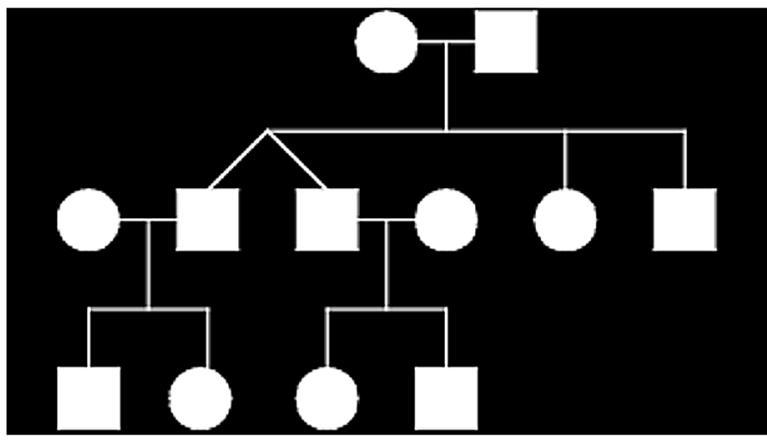

(a)

Fig. 4 a Idealized pedigree, b reproduced from Fig. 2 in Eaves et al. 1999a, c reproduced from Fig. 2 in Maes et al. 1996, d reproduced from Fig. 3 in Keller et al. 2009

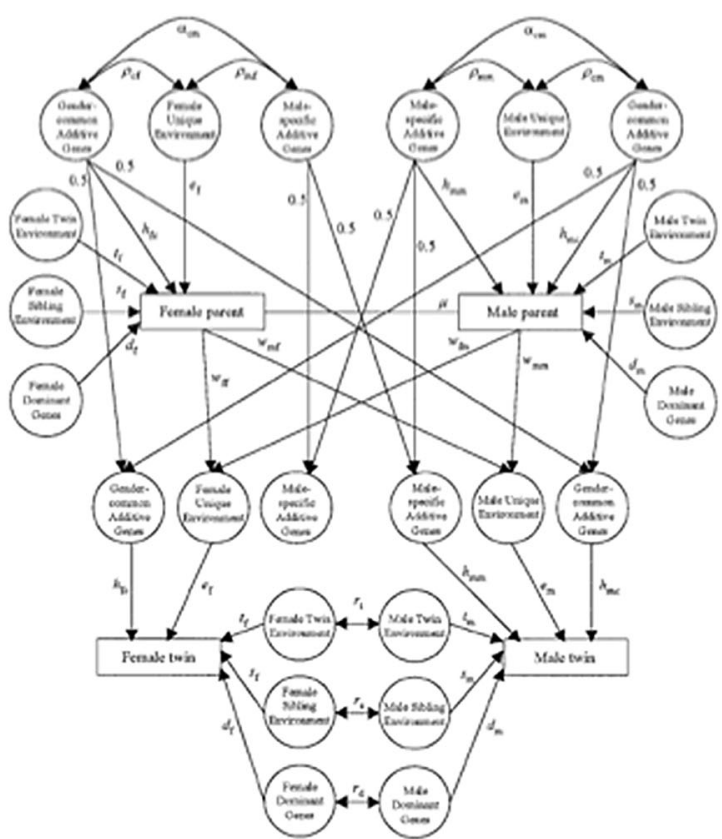

(b)

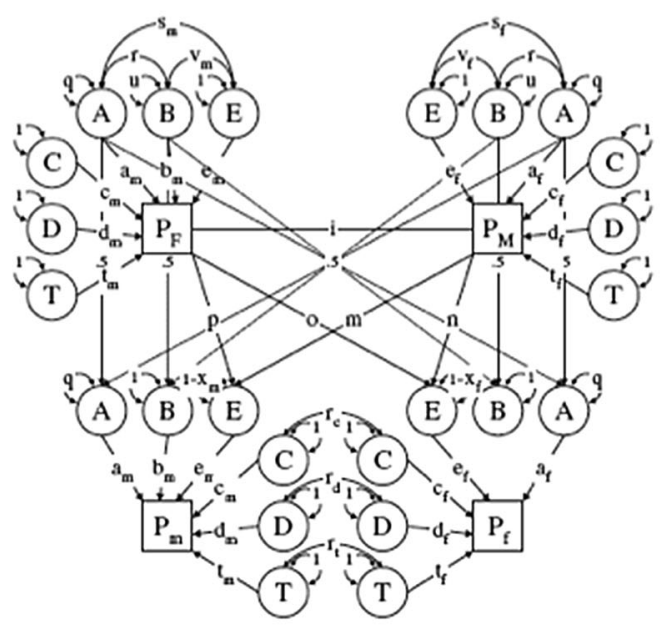

(c)

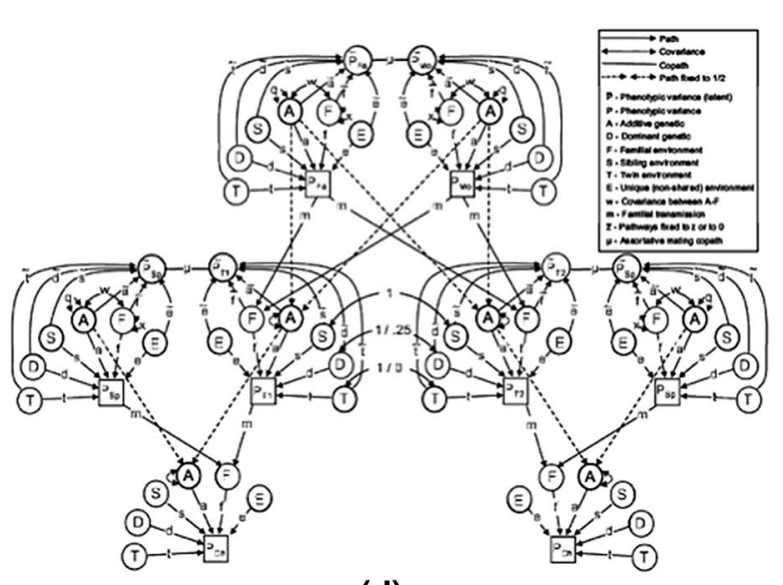

(d)

Fig. 4 continued 
Photo 4 Collage of photos taken by Hermine H. Maes over the course of several workshops in Boulder, Colorado, copyright (C) the author

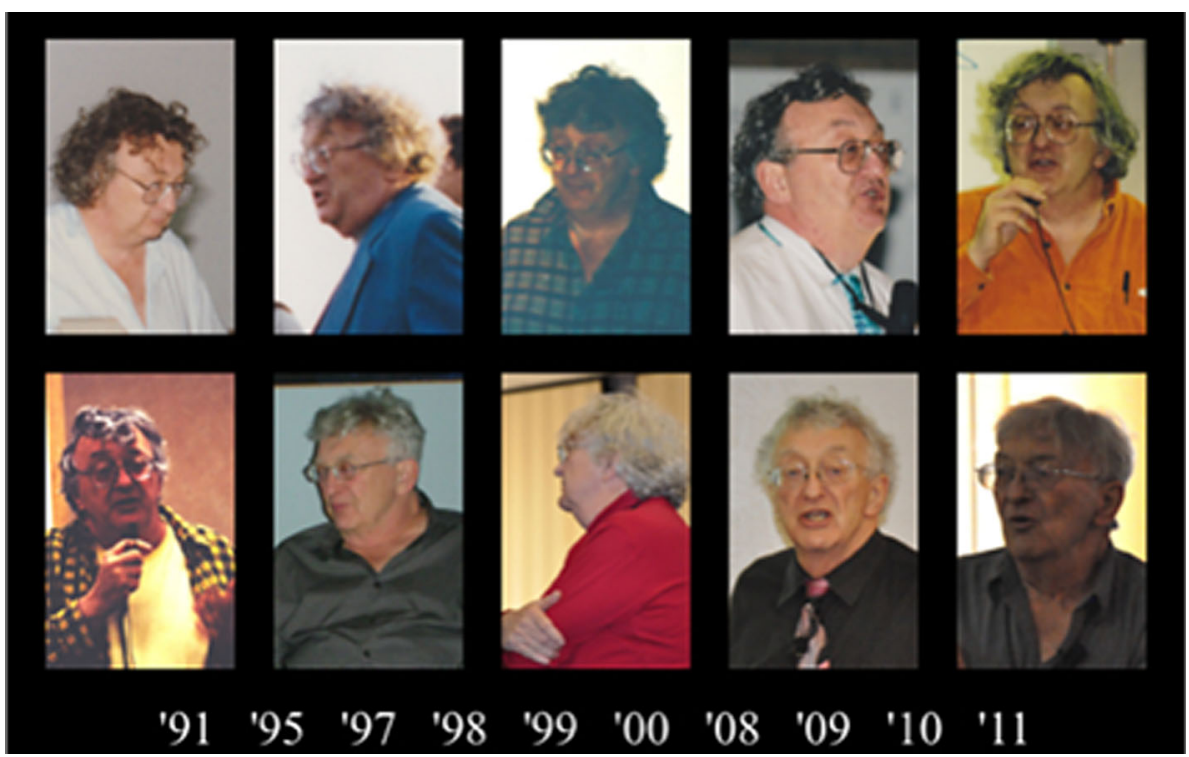

points higher than those between time points further apart from one another. In addition to the above mentioned transmissions from previous time points, and innovations, one might also be able to distinguish the effects of common factors across the various repeated measures (Fig. 5b) if data are collected over enough occasions (Eaves et al. 1986). Further extensions of these types of model may include the effects of sibling interaction and causal influences of previous on future behavior, as in a path diagram depicting the influence of habit on disease liability with sibling interaction (Fig. 5c) and growth curve models (Eaves 1988). Besides Lindon's insight into these now classic developmental models, he has been instrumental in testing the properties of these models and other models by extensive simulations to test, for example what the effect of a discrete milestone, like puberty, would be to the expected patterns of increasing/decreasing contributions of different sources of variation (Fig. 5d, Eaves 1988). Equally important are his power calculations to get estimates for the required sample sizes necessary to be able to distinguish between alternative hypotheses (Photo 5).

\section{Adolescent Behavioral Development: The Virginia Twin Study}

Evaluating hypotheses about genetic and environmental factors in development requires longitudinal genetically informative data. This need led to the design of the Virginia Twin Study of Adolescent Behavioral Development
Photo 5 Taken by Hermine H. Maes during 24th workshop in Boulder Colorado, 2010, copyright (C) the author
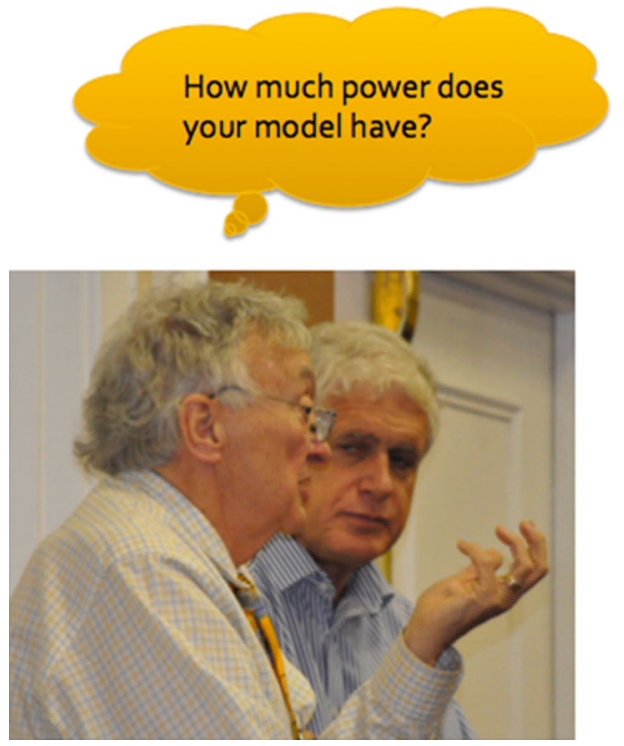

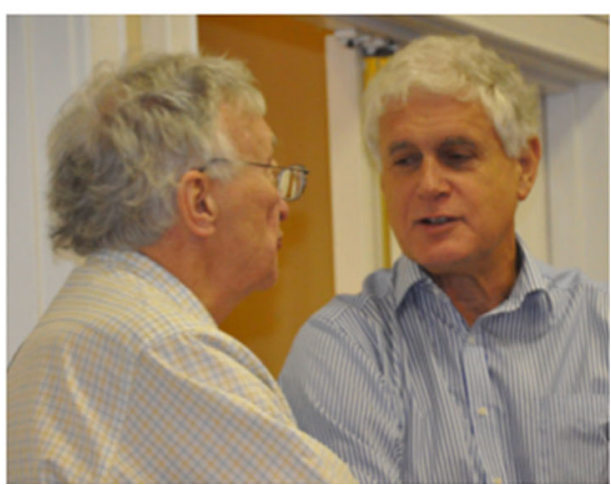




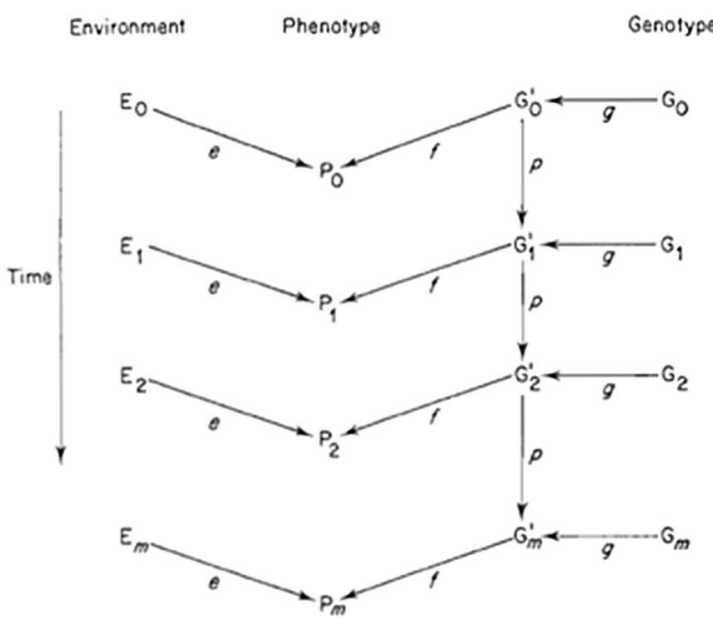

(a)

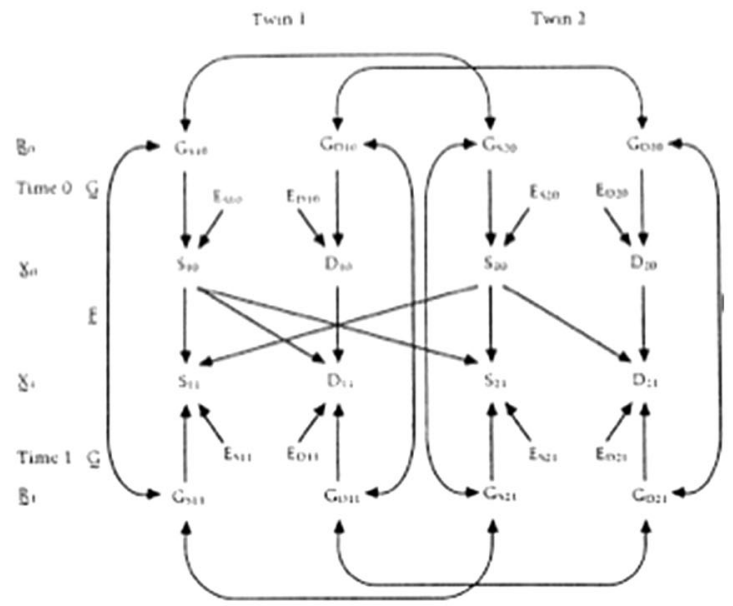

(c)

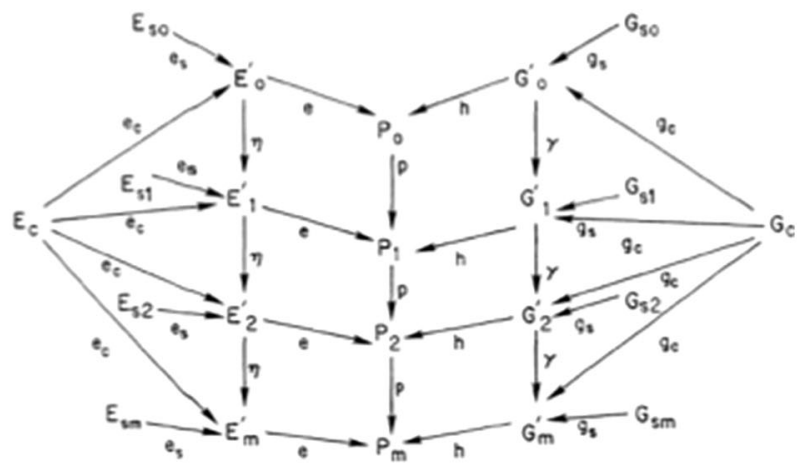

ENVIRONMENT PHENOTYPE GENOTYPE

(b)
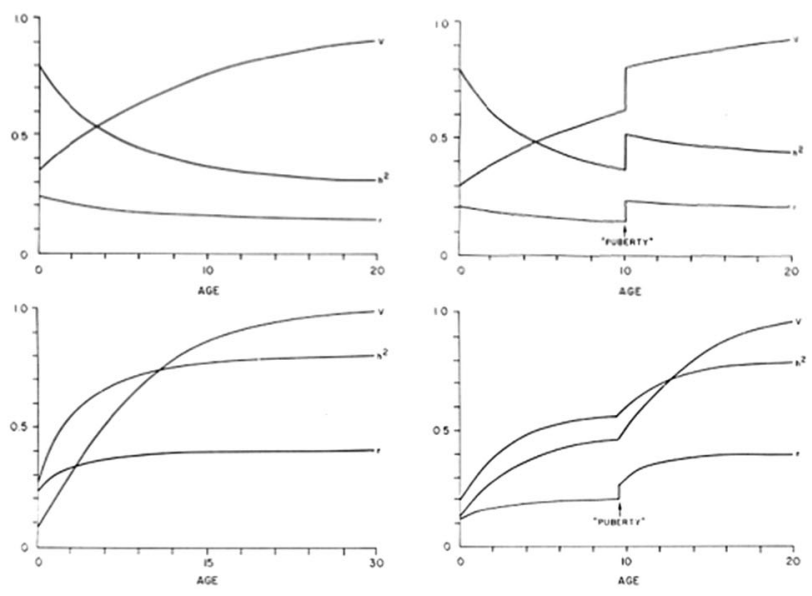

(d)

Fig. 5 a Reproduced from Fig. 7.2 in Eaves et al. 1989a, b reproduced from Fig. 1 in Eaves et al. 1986, c reproduced from Fig. 1 in Eaves et al. 1988, d reproduced from Figs. 2-5 in Eaves et al. 1986

(VTSABD (Eaves et al. 1997)) which is a cohort-sequential study design of adolescent twin measured repeatedly across adolescence and followed up in young adulthood (Fig. 6).

Given Lindon's interest in intergenerational transmission, parents were also ascertained not only to provide information about their own behavior, but also as additional raters on the child/adolescent behavior. As a result, the study has features that allow for a rich investigation of the sources of variation in a range of behavioral and psychiatric phenotypes across adolescent development. With

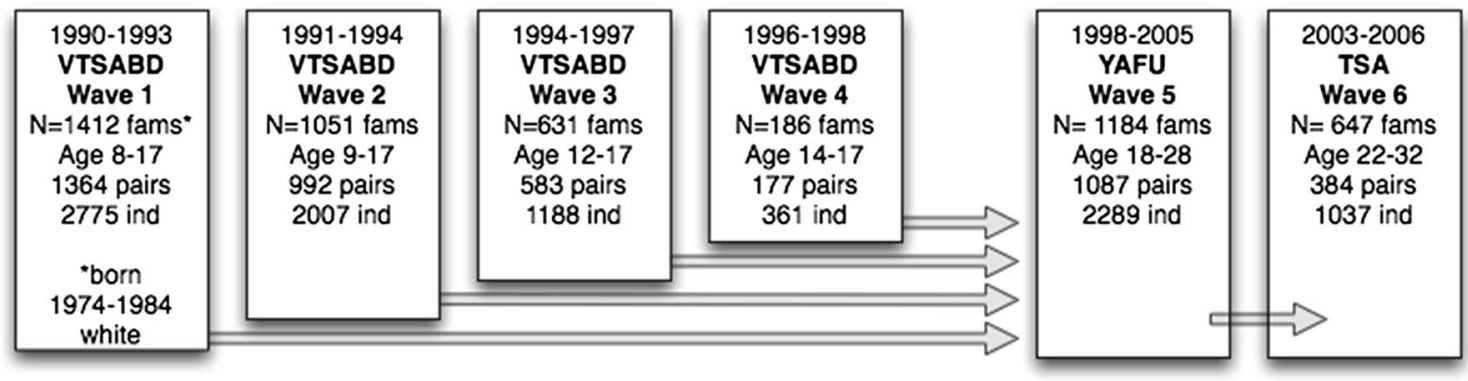

Fig. 6 Details from the Virginia Twin Study of Adolescent Behavior Development 


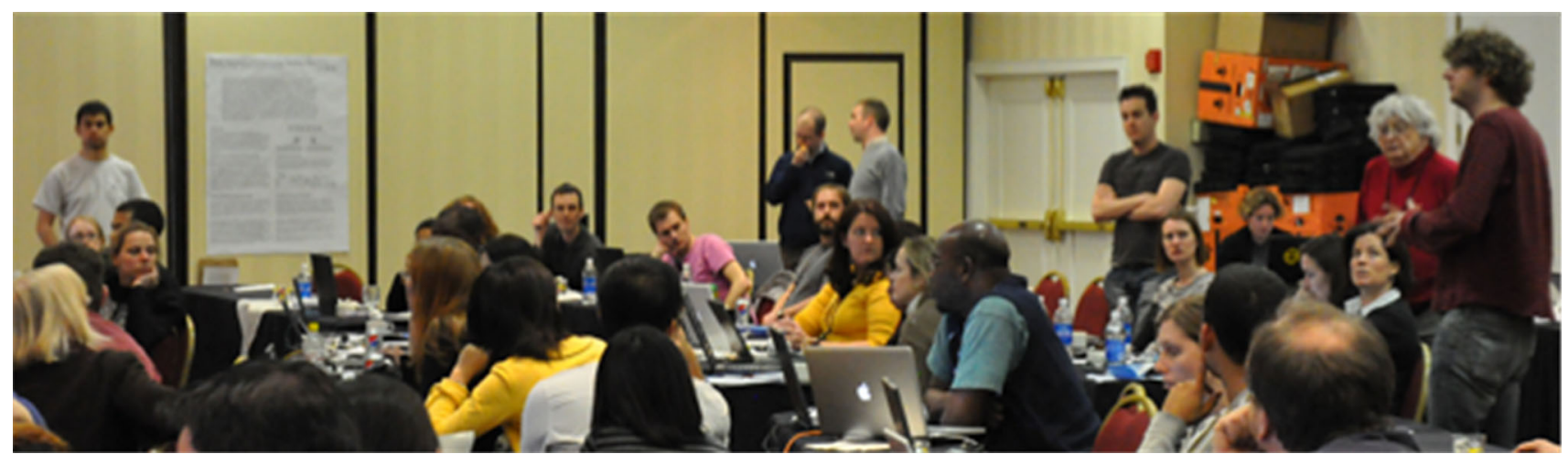

Photo 6 Taken by Hermine H. Maes during 23rd workshop in Boulder Colorado, 2009, copyright (C) the author

twin data, the whole arsenal of standard genetic epidemiological (ACE) modeling is available. The addition of parental data provides ways to estimate assortment and relative importance of genetic versus cultural transmission across generations. Data on both same-sex and opposite sex pairs allow tests of heterogeneity by sex, both in terms of differences in the magnitude and nature of the effects. The longitudinal nature of the design is of course key to testing alternative developmental hypotheses. The availability of ratings of the child/adolescent behavior by self-report, parental and teacher reports provides an avenue to testing for rater bias and contrast. A range of multivariate approaches, including factor analysis, item response modeling and latent class analysis can be applied to the rich phenotypic data, which includes both dimensional and categorical measures. Environmental indices can be used to test genotype by environment interaction and genotypeenvironment correlation. Survival models can be fitted to developmental milestones and age of onset data. Furthermore, the available measured genotype data (genome-wide arrays and targeted sequencing) allow for both exploratory and more confirmatory types of analyses and can use Mendelian randomization methods to evaluate direction of causation between outcomes (Photo 6).

To quote John Jinks, one of his mentors, in a discussion of Dr. Eaves' paper 'I could quote many examples to show that the number of genes found is proportional to the patience and effort which the experimenter is willing to put into their detection.' Lindon may not have found any specific genes (yet), but he has given us an amazing toolset that will help us enormously to decide whether we can believe the finding if we ever do find them.

\section{Note}

Lindon's contributions to the scientific literature are many, the number of co-authors (Fig. 7a) large and the number of citations (Fig. 7b) even larger. However, these numbers do not measure up to the quality and depth of his contributions, the lasting legacy in training the next generation of scientists (Fig. 8), not only in behavior genetics but the broader application of statistics, genetics and the social sciences. His desire to get it right through the scientific process of translating one's hypothesis into testable models that are fitted to data is laudable. In his words 'If you can write the model..... you can fit it (if you can get the data). The chances are...... that your real questions don't fit into this basic framework. Be creative... Imagine...' (Photo 7, 8).

Thank you, Lindon, for being generous, genius, gregarious, greatest, gifted, glorious and grand!

No single issue can capture the impact Lindon has had on the study of complex traits and quantitative genetics. Yet we are excited to introduce the compilation of papers brought together here. Alongside this introduction, three additional papers provide a review of Lindon's work. Lindon's first $\mathrm{PhD}$ student, Dr. Nicholas Martin, reviews Lindon's "first astonishing decade", the 1970's, which gave rise to his major theoretical advances in assortative mating, cultural transmission, sex limitation, sibling effects, gene-environment interaction and covariation, and multivariate genetic analysis. Drs. Kenneth Kendler and Michael Neale, who have worked alongside Lindon at the Virginia Institute for Psychiatric and Behavioral Genetics for the past 25 years, pick up where Dr. Martin leaves off, summarizing Lindon's major contributions to the field of psychiatric genetics, focusing on data collection methods, conceptualizations and data analytic methods, and his approach to science. Dr. Michael Neale then provides a synopsis of Lindon's essential role in the development of mixture modeling in genetic studies, which has informed current methods for genetic association, latent class analysis, growth curve mixture modeling, genotype by environment interaction, variance component twin modeling, and many others.

The issue continues with three methodological papers that reflect the spirit of Lindon's contributions to the field 


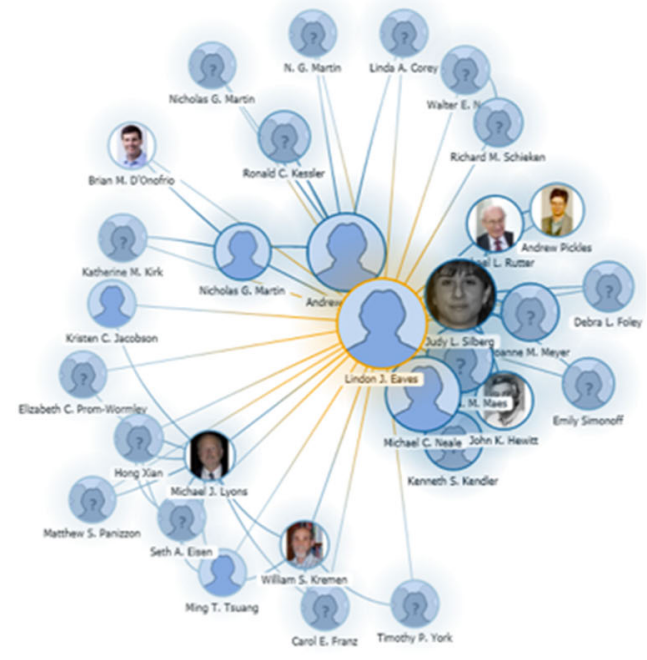

(a)

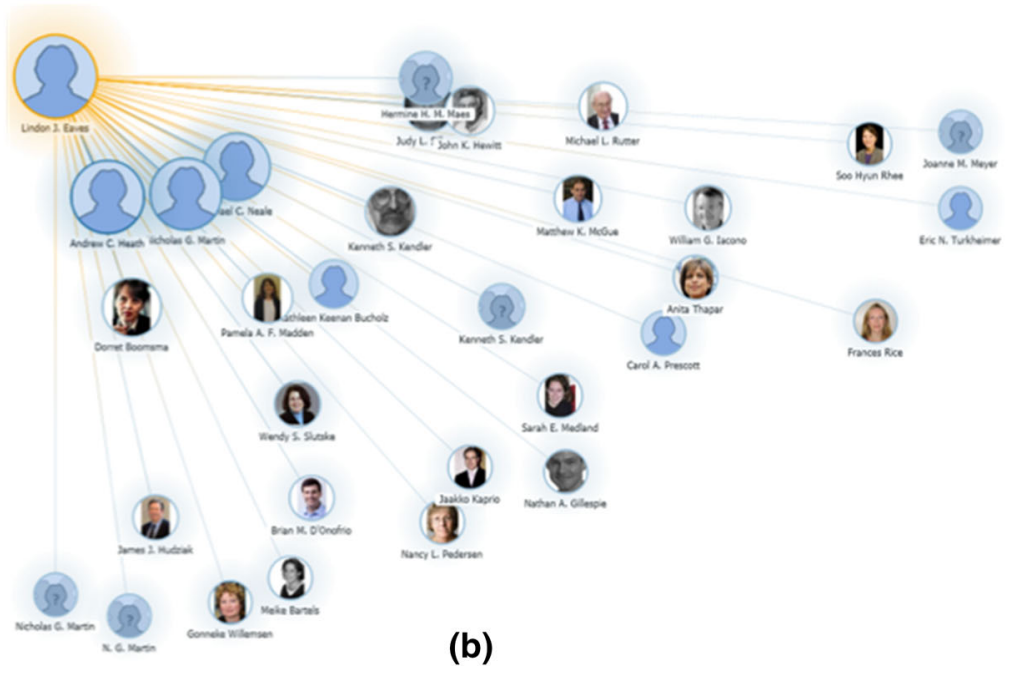

Fig. 7 a Graph generated with Microsoft academic search citation graph, b graph generated with Microsoft academic search co-author graph

of study. Drs. Dylan Molenaar and Conor Dolan illustrate the problems associated with testing for genotype by environment interactions on summed item scores within the ACE model. Dr. Gitta Lubke addresses the concern that current multivariate methods rely on the assumptions of phenotypic and genetic homogeneity, by introducing a distance-based regression technique to account for subgroups in the population, and differential genetic effects. Dr. Dolan addresses the issue of statistical power to detect phenotype to environment transmission in the ACE and
AE simplex models, as an approach to estimating G-E covariance.

The last few papers focus more on substantive traits in the psychiatric and social domains. Franic et al.'s multivariate genetic item analyses finds that internalizing syndrome dimensions are better understood as a composite of unconstrained genetic and environmental influences than as causally relevant entities generating the observed symptom covariation. Additionally, they find evidence of a common genetic basis for anxiety, depression, and withdrawn

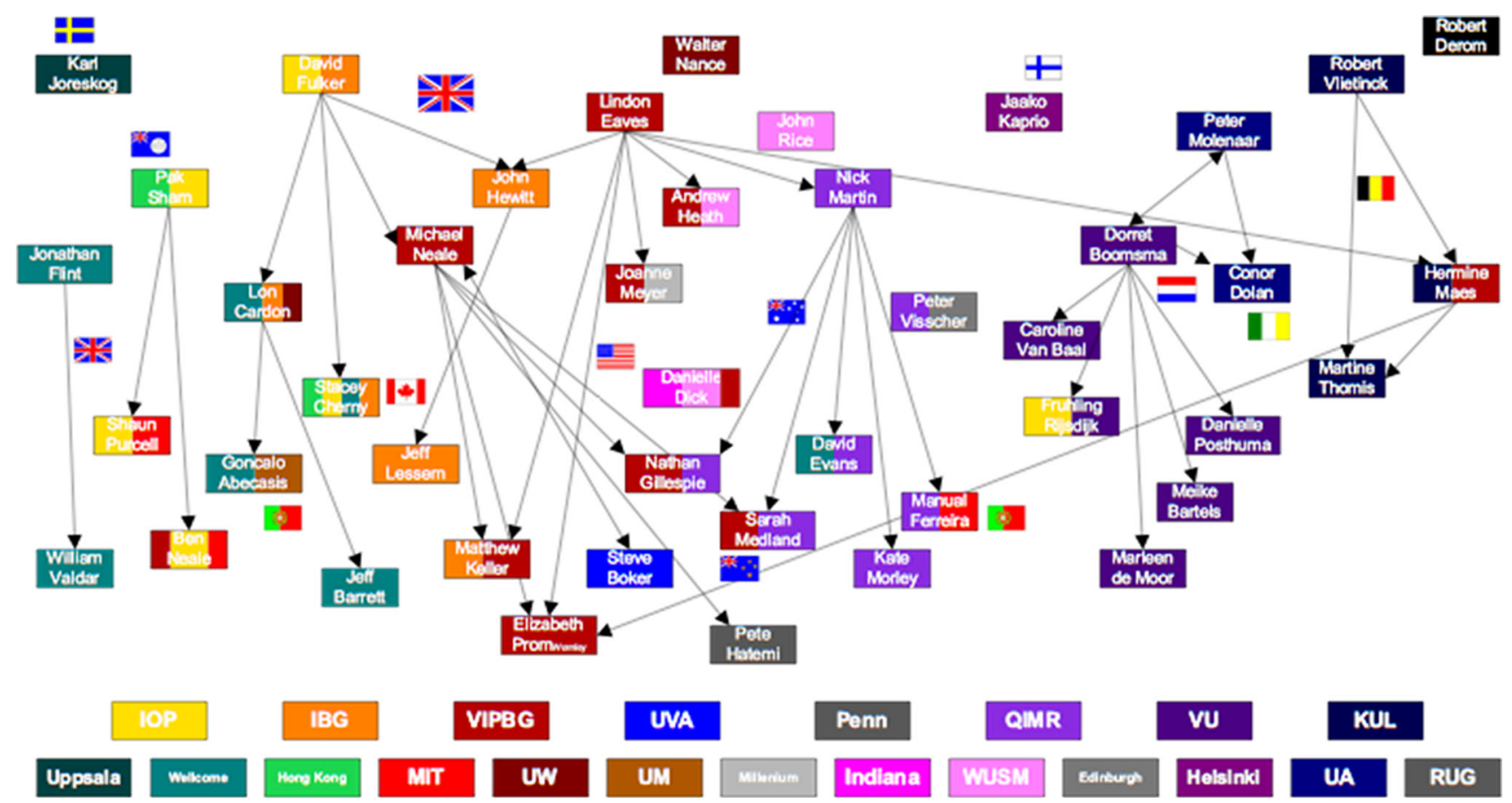

Fig. 8 Graph representing faculty who participated in several of the international workshops in Leuven, Belgium and Boulder, Colorado 
Photo 7 and 8 Taken by Hermine H. Maes during 26th workshop in Boulder Colorado, 2012, copyright (C) the author
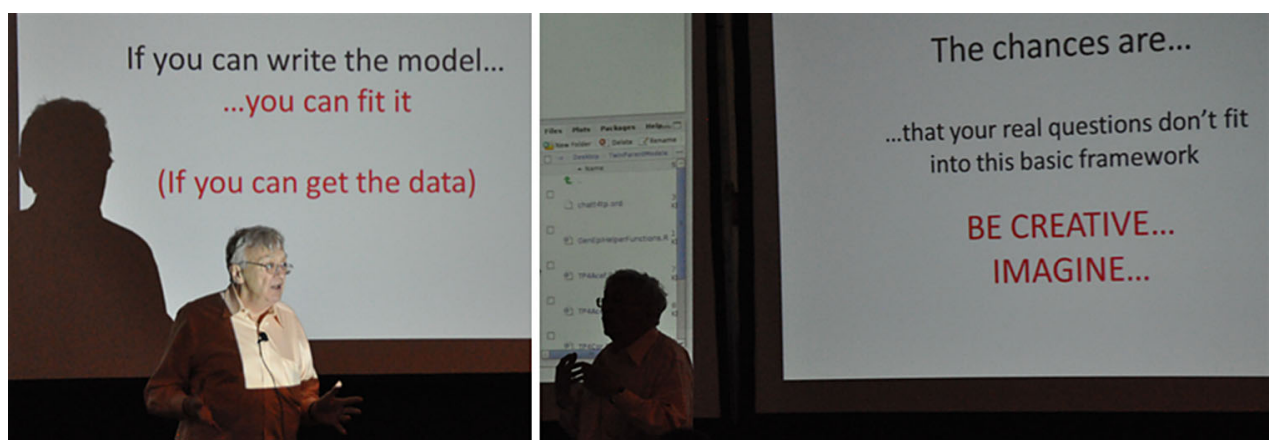

behavior, with the distinction between these syndromes being driven by the individual-specific environment. Mitchem et al. explore the question of whether genes influencing facial attractiveness and masculinity-femininity have similar, opposing, or independent effects across sex. They find evidence for intralocus sexual conflict, whereby alleles that increase masculinity in males have the same effect in females. Additionally, genetic influences on attractiveness were shared across the sexes, suggesting that attractive fathers tend to have attractive daughters and attractive mothers tend to have attractive sons. Finally, the issue closes with a study on social attitudes. This is fitting in many ways; social attitudes were initially used as a means by Lindon to validate the twin model with something that would be entirely "social". The original Eaves, Eysenck and Martin studies remained unaddressed in the social sciences until recently. Hatemi et al., revisit these studies, and conduct twin analyses on 19 scales of social attitudes and political ideologies from five democracies, across four decades and find evidence that genetic factors account for a substantial portion of the variation on social attitudes and political ideologies, regardless of how ideology is measured, the era, or the population sampled. They also present the results from one of the first genome-wide association studies on political ideology using data from three samples.

We hope that the pleasure we had organizing and participating in the festschrift in Edinburgh in 2012, and in assembling this issue, shines through. It is also our hope that you the reader will find the articles intriguing and stimulate further extensions and applications of the methods and models which define our field and were originally introduced by Professor Lindon Eaves.

Acknowledgments Supported by DA025109 and MH019918.

\section{References}

Boker S, Neale M, Maes H, Wilde M, Spiegel M, Brick T, Spies J, Estabrook R, Kenny S, Bates T, Mehta P, Fox J (2011) OpenMx: an open source extended structural equation modeling framework. Psychometrika 76(2):306-317
Eaves LJ (1972) The utility of twins. Genetic basis of the epilepsies. In: Anderson VE, Hauser WA, Penry JK, Sing CF (eds), New York, Raven Press, p 249-276

Eaves L (1976) The effect of cultural transmission on continuous variation. Heredity (Edinb) 37(1):41-57

Eaves LJ (1979) Basic issues in the analysis of human differences. Prog Clin Biol Res 32:475-487

Eaves LJ, Hewitt JK, Heath AC (1988) Human developmental change. In: Weir BS, Eisen EJ, Goodman MM, Namkoong G (eds) Proceedings of the second international conference on quantitative genetics, Sinauer, Sunderland

Eaves LJ, Last KA, Young PA, Martin NG (1978) Model-fitting approaches to the analysis of human behaviour. Heredity (Edinb) 41(3):249-320

Eaves LJ, Long J, Heath AC (1986) A theory of developmental change in quantitative phenotypes applied to cognitive development. Behav Genet 16(1):143-162

Eaves LJ, Eysenck HJ, Martin NG (1989a) Genes, culture and personality: an empirical approach. Academic Press Inc., San Diego

Eaves LJ, Fulker DW, Heath AC (1989b) The effects of social homogamy and cultural inheritance on the covariances of twins and their parents: a LISREL model. Behav Genet 19(1):113-122

Eaves LJ, Silberg JL, Meyer JM, Maes HH, Simonoff E, Pickles A, Rutter M, Neale MC, Reynolds CA, Erikson MT, Heath AC, Loeber R, Truett KR, Hewitt JK (1997) Genetics and developmental psychopathology: 2. The main effects of genes and environment on behavioral problems in the Virginia Twin Study of Adolescent Behavioral Development. J Child Psychol Psychiatry 38(8):965-980

Eaves L, Heath A, Martin N, Maes H, Neale M, Kendler K, Kirk K, Corey L (1999a) Comparing the biological and cultural inheritance of personality and social attitudes in the Virginia 30,000 study of twins and their relatives. Twin Res 2(2):62-80

Eaves LJ, Heath AC, Martin NG, Neale MC, Meyer JM, Silberg JL, Corey LA, Truett KR, Walters E (1999b) Biological and cultural inheritance of stature and attitudes. Personality and psychopathology. American Psychiatric Press Inc., Washington, pp 269-308

Keller MC, Medland SE, Duncan LE, Hatemi PK, Neale MC, Maes HH, Eaves LJ (2009) Modeling extended twin family data I: description of the Cascade model. Twin Res Hum Genet 12(1):8-18

Lilley EC, Silberg JL (2013) The Mid-Atlantic Twin Registry, revisited. Twin Res Hum Genet 16(1):424-428

Maes HH, Beunen GP, Vlietinck RF, Neale MC, Thomis M, Vanden Eynde B, Lysens R, Simons J, Derom C, Derom R (1996) Inheritance of physical fitness in 10-year-old twins and their parents. Med Sci Sports Exerc 28(12):1479-1491

Neale MC, Boker SM, Xie G, Maes HH (2006) Mx: Statistical Modelling, 6th edn. Department of Psychiatry, Richmond 